\title{
Behavior study of freshwater prawn Macrobrachium assamense peninsulare in aquarium culture
}

\begin{abstract}
Based on visual and video graphic examination behavioral study of Macrobrachium assamense peninsulare was designed for one year. It was concluded that the prawn was omnivore in nature and mostly prefer animal food as compared to plant food. The fecundity of 30-100 eggs in a single spawning was observed one year confirms that the animal is an annual breeder. The ecological conditions of the aquarium were maintained at 26 Celsius $\left({ }^{\circ} \mathrm{C}\right)$ with neutral $\mathrm{pH}$ throughout the study. The ecological conditions play a vital role in the development and maturity of the prawn. Food intake in animals was seen as poor during the breeding session as compared to the other period of life cycle.
\end{abstract}

Volume 9 Issue 6 - 2020

\author{
Koshal Kumar \\ Department of Zoology, H N B Garhwal University, India
}

Correspondence: Koshal Kumar, Department of Zoology, H N B Garhwal University, India, Email koshlbagelu@gmail.com

Received: November 26, 2020 | Published: December 28, 2020

Keywords: behavior, freshwater prawn, aquaculture

\section{Introduction}

The ethological study of freshwater prawns in India is very alarmed, particularly in the hill area. No such studies on behavioral ecology on minor freshwater prawns have been made till date from Uttarakhand. An immense need to intensify prawn production through culture has urged an interest in the encouragement of breeding commercially. Lack of local availability of seed in Indian for the commercial culture of prawn is a big issue to the breeders. Ling, ${ }^{1}$ has successfully induced breeding in Macrobrachium rosenbergii in Malaya and similar experiments have been attempted by Mallikarjuna ${ }^{2}$ at the Central Inland Fisheries Research Institute, Barrackpore by study the behaviore of Macrobrachium rosenbergii. Several studies have been conducted for the prawns behavior and growth by different workers, Singh et $\mathrm{al}^{3}$ on Macrobrachium gangetisum; Soundarapandian et. al., ${ }^{4}$ on Macrobrachium idea and Santos et. al., ${ }^{5}$ on Macrobrachium rosenbergii etc in different location and found a countless variation in study. Such study has been not made on minor prawns in aquarium culture till date. During this study, several interesting aspects of the behaviors of Macrobrachium assamense peninsulare have been observed, which is presented in this paper.

\section{Methodology}

Fresh female and male sample of the prawn was collected from the Dugadda site in river Khoh a tributary of river Ganga in Central Himalaya region India during the daytime with the help of Sieve or handpicking methods. The collected animals were transported carefully by avoiding embryos from any stress/hurt. Transportation was under the Oxygenated polythene bags kept inside the bucket by road from Dugadda to the Aquatic Laboratory in Department of Zoology, BGR Campus HNB Garhwal University, Pauri Garhwal by covering a distance of $100 \mathrm{~km}$.

Immediate after reaching the laboratory, packets were open and prawn was released in the rearing tank of $6 \times 3 \times 2$ feet dimension having pre maintained ecological conditions of water the temperature ranges from $24-26^{\circ} \mathrm{C}, \mathrm{pH} 6-7$ and dissolved oxygen ranges from 4-6ppm. The prawn was feed with the Oil cakes and fish feed or by egg albumin by rotation twice a day. Proper aeration and cleaning of the tank were done to remove the refused food matter and water was changed accordingly. All behavioral activity including feeding and breeding behavior were observed by visual methods and sometimes Sony ${ }^{\circledR}$ HDR-PJ410 Digital HD Video Camera was used for video recording.

\section{Observations and discussion}

During the study all recording was made using Video camera in both night and in the day time, the observation was recorded in the aquarium as following (Figure 1)

1. The Macrobrachium assamense peninsulare are mainly hiding them self-form light phage and sitting on the wall or material present in the aquarium.

2. Male was observed to take more food freely before mating as compared to the female, the individual show cannibalism, and prefer animal food as compared to the plant matter hence called omnivores and the result was in agreement with the result of Raman, Rao, Coasta and Wanninayake ${ }^{6,7,8}$ who have reported that prawn are omnivores in feeding habitat

3. The female in the initial stage of the development hides shows an avoidance reaction by moving away from the male to the corner and by hiding themselves under the stone. The male does not pay the intention of females and busies by brushing its antenna and pincer with the help of its first pair of chelipeds and other body parts with the last pair of thoraces legs.

4. The moment of the female is less as compared to the male individuals and mating does not take place in the ordinary condition of the female. Some special "ripe" condition is needed for the attraction of female. The female after a prespawning moult and enter into puberty only are attractive to males and undergo in the cage or under a stone for 6-10 hours after the pre-spawning moult.

5. When two male was introduced for mating with a single ripe female in a cage a sexual fight was seen for about 10-20 minutes. The male facing each other in the opposite direction and performing a fighting poster "threat or bluff position Tinbergen, ${ }^{9}$ this behavior was repeated for interval and time.

6. Coupling was performed at the bottom of the aquarium, as rapidly as a female gets completely respondent the coupling 
follows, the female lies on its back beneath the male at an angle of 20-30 degrees make in a style of scissors by crossing their bodies with each other. The conditions last for 15-30 seconds, during which the sperm deposition takes place, a similar observation was made in Palaemon squilla. ${ }^{10}$

7. Soon after the mating male relaxed beside the female for five to 10 minutes, then it protects the female from other males showing tertiary behavior by enclosing the female within its log chelipeds, and eagerly guarding it, a similar observation was seen in Macrobrachium rosenbergii.

8. Spawning of eggs takes place after the day of copulation mainly. During and after spawning the female leaves the bottom habitat and come to the wall of stick on the substantial objects in the aquarium. Half an hour was taken to deposit the egg on pleopods. Morphological changes were observed in this time orange in color cephalothorax changed to a dark patch and gonadal maturation, which occupy major portion of the cephalothorax and well compared with the studies of $M$. malcolmsoni Ibrahim. ${ }^{11}$ The thoraces leg helps to orient eggs to the ovigerous seta on the first 4 pairs of pleopods. The females are observed to breed only once during June to September every year, hence this period is considered as the breeding season of the $\mathrm{M}$. assamense peninsular, and the animal is kept under the annual breeder category.

9. The berried female starts feeding and consumes food vigorously and continuously showing the moments of pleopods to aerate the eggs throughout the incubation periods.

10. Incubation periods lasted for 18-19 days, the eggs hatch out into larva when water conditions were temperature 26 degrees and dissolved oxygen 3-7ppm, $\mathrm{pH} 7-8$ and only a few reports are available on these aspects in some species, particularly $M$. rosenbergii, ${ }^{12} \mathrm{M}$. nobilii, ${ }^{13}$ and $M$. lanchesteri ${ }^{7}$ and larva need more care of water physicochemical properties and maintained daily.

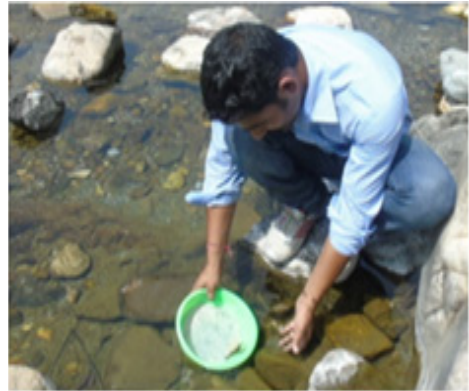

(a)

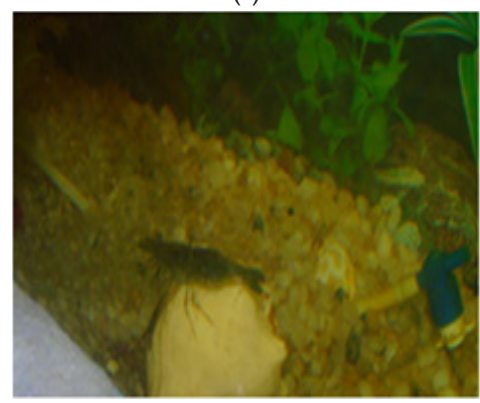

(d)

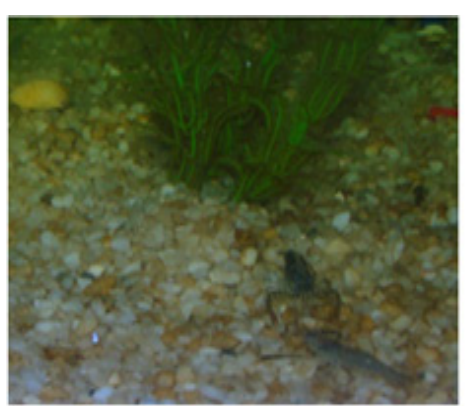

(b)

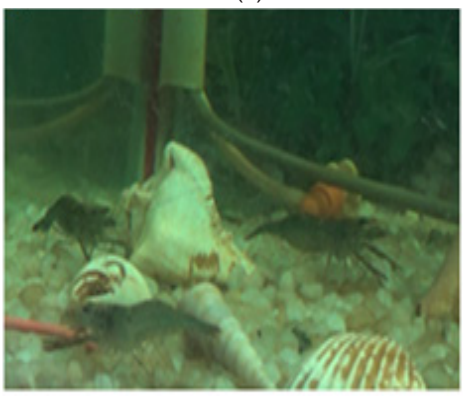

(e)

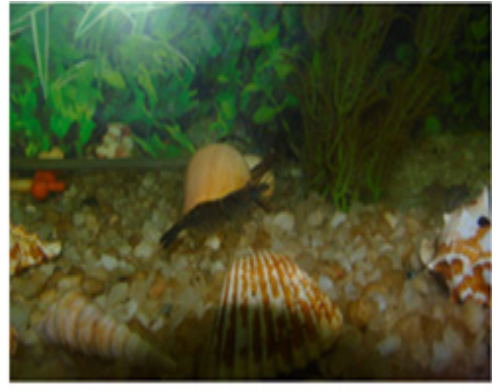

(c)

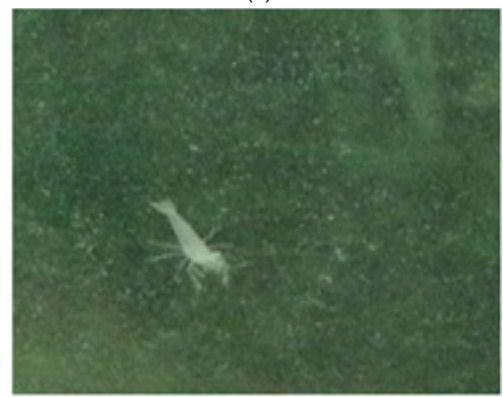

$(f)$

Figure I a) Sampling process in Khoh stream; (b) Mating behavior in the aquarium; (c) Female on Bottom in the aquarium; (d) Gravid female in an aquarium; (e) Female before egg-laying; ( $f$ ) Early Hatched Larva in the aquarium.

\section{Conclusion}

The study concluded that the Macrobrachium assamense peninsulare would be highly recommended for culture and that this process help in the production of species that threaten by the environment. It is important to pay attention to study the effects of various environmental conditions on animal welfare in farming, emphasizing what gives the animal's great freedom to express their natural behaviour. This approach will probably increase population status of animal growth, breeding outcome and reduce the production expenses.

\section{Acknowledgments}

Author is gratefully acknowledge the HOD Department of Zoology, BGR Campus Pauri HNBGU for providing all facilities for conducting this study and to meet the contingent expenditure.

\section{Data availability statement}

The data that support the findings of this study are not publicly available due to privacy or ethical restrictions.

\section{Conflicts of interest}

Author has declared no conflict of interest.

\section{References}

1. Ling SW. The general biology and development of M. rosenbergii. FAO Fish. 1961;57(3):607-619.

2. Mallikarjuna Rao R. Breeding behaviour in Macrobrachium rosenbergii (De Man). Fishery Technology. 1965;2(1):19-25.

3. Singh AK, Tiwari RK, Khanaujia RD, et al. Growth and breeding behavior of Macrobrachium gangetisum in River Ganga around Varanasi. Ecologia. 2012;2(2):31-42. 
4. Soundarapandian P, Sudhakar S, Varadharajan D, et al. Mating Behaviour in Different Size Males of Macrobrachium idae (Heller, 1862). J Cytol Histol. 2013;5:205.

5. Santos DB, Pontes CS, Campos PMO, et al. Behavioral profile of Macrobrachium rosenbergii in mixed and monosex culture submitted to shelters of different colors. Acta Scientiarum Biol Sci Maringá. 2015;37(3):273-279.

6. Raman K. Observation of the fishery and biology of the giant freshwater prawns Macrobarchium rosenbergii de Man. Proc Symp Crustacea Mar Biol Ass India Part-2.1967; p: 649-669.

7. Rao CN, Shakuntala K, Reddy SR. Moult reproduction relationship in the freshwater prawn, M lanchesteri (de Man). Proc Indian Acad Sci. 1981;90(1):39-52.

8. Coasta HH, Wanninayake TB. Food, feeding and fecundity of the giant fresh water prawn, Macrobrachium rosenbergii from a natural habitat in Sri Lanka. 1st Asian Fish Forum. 1986;555-558.
9. Tinbergen N, Perdeck AC. On the stimulus situation releasing the begging response in the newly hatched Herring Gull chick (Larus argentatus argentatus Pont.). Behaviour. 1951;3(1):1-39.

10. Hoglund H. On the biology and larval development of Leander squilla (L.) forma mica de Man. Svenska Hydrografisk-Biologiska Komrnissionens skr. Ny serie: Biologi.1943;11(6):1-44.

11. Ibrahim KH. Observations on the fishery and biology of the freshwater prawn Macrobrachium malcolmsonii of the river Godavari. Indain J Fish. 1962;9(2):433-467.

12. Sandifer PA, Smith TIJ. Freshwater prawns. In Crustaceans and Mollusk Aquaculture in United State. Huner JV and Brown EE, editors. AVI Publishing Westpot CT. 1985;63-123.

13. Pandian TJ, Balasundaram C. Molting and spawning cycles in M nobilii (Henderson and Matthai). Int J Inver Rep Dev. 1982;5(1):21-30. 